\title{
Increased Left Ventricular End-Diastolic Pressure after Left Ventriculography is Associated with Subsequent Congestive Heart Failure-Related Hospitalization
}

\author{
Tomitaka Wakaki, Naoki Ishibashi, Hidetsugu Yamao \\ Cardiology, Kitaibaraki City Hospital, Kitaibaraki, Japan \\ ORCID: \\ Tomitaka Wakaki: https://orcid.org/0000-0003-3970-3830 \\ Naoki Ishibashi: https://orcid.org/0000-0001-7364-5764 \\ Hidetsugu Yamao: https://orcid.org/0000-0002-6518-1151
}

\section{Abstract}

Context: Left ventricular end-diastolic pressure (LVEDP) reportedly increases after left ventriculography (LVG), and patients with congestive heart failure (CHF) tend to have high LVEDP. We hypothesized that increased LVEDP after LVG is directly associated with hospitalization for CHF. Aims: This study aims to investigate whether a predictive association exists between increased LVEDP after LVG and CHF-related hospitalization. Settings and Design: This was retrospective, single-center (hospital), observational study. Subjects and Methods: We analyzed data of 68 consecutive patients who underwent LVG between March 2015 and July 2017. Patients were divided into the following two groups: those with $\triangle$ LVEDP $\geq 6 \mathrm{mmHg}$ during LVG and those with $\triangle \mathrm{LVEDP}<6 \mathrm{mmHg}$ during LVG. The two groups had similar baseline characteristics, except for body mass index. Statistical Analysis Used: Multivariate Cox proportional hazards analysis was used to determine whether increased LVEDP was associated with CHF-related hospitalization. Results: During the follow-up period (median duration [interquartile range]: 699 [413-994] days), eight patients $(11.8 \%)$ were hospitalized for CHF. The risk of CHF-related hospitalization was significantly higher in the group with $\triangle \mathrm{LVEDP} \geq 6 \mathrm{mmHg}$ than in the group with $\triangle$ LVEDP $<6 \mathrm{mmHg}$ (hazard ratio, 8.4; 95\% confidence interval, 1.3-55.7). A Kaplan-Meier analysis confirmed this finding $(P=0.002)$. Conclusions: Increased LVEDP after LVG is an independent predictor of CHF-related hospitalization. Determining $\triangle L V E D P$ values may facilitate the identification of patients who should undergo early interventions because they are at risk of CHF-related hospitalization.

Keywords: Congestive heart failure, hospitalization, left ventricular end-diastolic pressure, left ventriculography, risk factors

\section{INTRODUCTION}

Left ventricular (LV) diastolic dysfunction can be identified by measuring LV end-diastolic pressure (LVEDP). High LVEDP is a risk factor for cardiovascular events, ${ }^{[1-6]}$ and elevated LVEDP likely increases ventricular wall stress and pulmonary congestion risk $^{[7]}$ due to decreased perfusion pressure, microvascular dysfunction, subendocardial oxygen delivery, and sympathetic and neurohormonal activation. ${ }^{[8,9]}$ LVEDP reportedly increases after left ventriculography (LVG), ${ }^{[10-13]}$ and patients with congestive heart failure (CHF) tend to have high LVEDP. ${ }^{[14]}$ However, no study has investigated whether

\section{Received: 02-12-2020 Revised: 21-12-2020 Accepted: 19-01-2021}

Published Online: 29-03-2021

\begin{tabular}{|l|l|}
\hline \multicolumn{3}{|c|}{ Access this article online } \\
\hline Quick Response Code: & Website: \\
& \\
http://www.ijcva.com
\end{tabular}

a predictive association exists between increased LVEDP after LVG and CHF-related hospitalization. We thus aimed to investigate this hypothesis.

\section{Subjects and Methods}

\section{Research ethics}

The study protocol was approved by the ethics committee of (blinded) City Hospital (approval number blinded). This

Address for correspondence: Tomitaka Wakaki, Kitaibaraki City Hospital, 1050, Sekimotoshimo Sekinamicho, Kitaibaraki City, Ibaraki Prefecture, 319-1711, Japan. E-mail: m06104tw@jichi.ac.jp

This is an open access journal, and articles are distributed under the terms of the Creative Commons Attribution-NonCommercial-ShareAlike 4.0 License, which allows others to remix, tweak, and build upon the work non-commercially, as long as appropriate credit is given and the new creations are licensed under the identical terms.

For reprints contact: WKHLRPMedknow_reprints@wolterskluwer.com

How to cite this article: Wakaki T, Ishibashi N, Yamao H. Increased left ventricular end-diastolic pressure after left ventriculography is associated with subsequent congestive heart failure-related hospitalization. Int J Cardiovasc Acad 2021;7:14-20. 
study was conducted in accordance with the principles of the Declaration of Helsinki. The requirement for informed written consent was waived for all participants due to the retrospective nature of the study.

\section{Study population}

For this retrospective, single-center, observational study, we reviewed electronic health records to obtain data concerning 91 patients who consecutively underwent LVG at our hospital between March 2015 and July 2017. We excluded patients for whom LVEDP data were unavailable $(n=3)$, patients with follow-up durations of $<30$ days $(n=13)$, patients who underwent bypass surgery immediately after their examinations $(n=3)$, patients who were hospitalized for stroke $(n=2)$, and patients who underwent percutaneous coronary interventions after their examinations $(n=2)$, leaving a sample of 68 patients.

\section{Clinical data and endpoint}

Hypertension was defined as a systolic blood pressure of $\geq 140 \mathrm{mmHg}$ or a diastolic blood pressure of $\geq 90 \mathrm{mmHg}$ at presentation, a medical diagnosis of hypertension, or the use of antihypertensives. Diabetes mellitus was defined as a fasting blood glucose value of $\geq 126 \mathrm{mg} / \mathrm{dL}$, a medical diagnosis of diabetes, or the use of antidiabetic medication. Dyslipidemia was defined as a total serum cholesterol concentration of $>220 \mathrm{mg} / \mathrm{dL}$, a medical diagnosis of dyslipidemia, or the use of lipid-lowering medications. Patients were considered smokers if they had ever smoked. The Japanese glomerular filtration rate (GFR) equation was used to calculate the estimated GFR (eGFR) as follows: eGFR $\left(\mathrm{mL} / \mathrm{min} / 1.73 \mathrm{~m}^{2}\right)=1.94 \times(\text { creatinine })^{-1.094}$ $\times$ age ${ }^{-0.287}$ (with the result being multiplied by 0.739 for women). ${ }^{[15]}$ Chronic kidney disease was defined as an eGFR of $<60 \mathrm{~mL} / \mathrm{min} / 1.73 \mathrm{~m}^{2}$ at admission. Patients with atrial fibrillation were defined as those presenting with atrial fibrillation at admission and those for whom paroxysmal atrial fibrillation had been noted in the past. Patients' admission symptoms were classified using the New York Heart Association (NYHA) functional classification. The primary endpoint was CHF-related hospitalization during the observation period. CHF-related hospitalization was defined as a patient who was considered hospitalized for respiratory failure due to $\mathrm{CHF}$.

\section{Data collection and left ventriculography data work-up}

Catheterization laboratory databases were accessed to obtain LVG data. The LV ejection fraction (LVEF) and LVEDP were measured with LVG after coronary angiography. LVG was performed with a 4-French pigtail catheter inserted into the left ventricle using a radial or femoral approach. LVEDP was recorded just before and after the contrast agent was injected and was measured at the Z-point, which was identified on an LV pressure trace as the point at which the slope of the ventricular pressure upstroke changed. Patients with atrial fibrillation adopted an average of four heartbeats. LVG was performed using $35 \mathrm{~mL}$ of $370-\mathrm{mg} / \mathrm{mL}$ iopamidol in all cases. $\triangle$ LVEDP values were calculated by subtracting pre-LVG LVEDP values from post-LVG LVEDP values. LVEF was calculated by subtracting the LV end-systolic volume (LVESV) from the LV end-diastolic volume (LVEDV) and dividing the difference by the LVEDV. LVESV and LVEDV were determined by tracing the ventricular margin. A 20-mm ball was used for comparison. The LV stroke volume (LVSV) was calculated as the difference between the LVEDV and LVESV. The LVESV, LVEDV, and LVSV values were indexed to the body surface area. Systolic blood pressure, diastolic blood pressure, and heart rate were determined using arterial pressure at the time of catheterization. Periodic echocardiography, blood tests, atrial natriuretic peptide measurements, and brain natriuretic peptide measurements were not performed for many of these patients.

\section{Statistical analysis}

All statistical analyses were performed with EZR (Saitama Medical Center, Jichi Medical University, Saitama, Japan), which is a graphical user interface for R (The R Foundation for Statistical Computing, Vienna, Austria). It is a modified version of $\mathrm{R}$ Commander designed to add the statistical functions that are frequently used in biostatistics. ${ }^{[16]}$ Data distributions were checked with the Kolmogorov-Smirnov test. Continuous variables with normal distributions were expressed as means with standard deviations, and continuous variables with non-normal distributions were expressed as medians with interquartile ranges. Student's $t$-test was used to compare continuous variables with normal distributions, and the MannWhitney U-test was used to compare continuous variables with nonnormal distributions. Categorical data were compared using Fisher's exact test. Cox proportional hazards analysis was used to identify independent predictors of CHF-related hospitalization during the observation period. We incorporated known risk factors for CHF-related hospitalization from past reports (such as high blood pressure, coronary artery disease, diabetes, smoking, and body mass index [BMI]) in the analysis. CHF-related hospitalizations were plotted against time, and log-rank analysis was performed with the Kaplan-Meier method. Receiver operating characteristic analyses were used to select a cutoff $\triangle$ LVEDP value that could be used to predict CHF-related hospitalization. The cutoff value closest to the upper left corner was used. $P<0.05$ was considered to indicate statistical significance.

\section{RESULTS}

The patients were mainly elderly because of the demographics of the area. Of the 91 patients, we analyzed the clinical data of 68 patients who had undergone LVG and for whom hemodynamic data were available. Our sample of 68 patients comprised $55(80.8 \%)$ with suspected ischemic heart disease for whom catheterization had been performed and $13(19.1 \%)$ with suspected CHF.

The 68 patients included in the analyses and the 23 patients excluded from the analyses were well matched in terms of their baseline characteristics. However, the excluded patients 
were more likely to have used aspirin before LVG $(P=0.003)$ and have higher creatinine levels $(P=0.019)$ [Table 1]. No patients had NYHA $\geq 3$ in this study. Only $4.4 \%(3 / 68)$ of the patients had moderate valvular heart disease.

The receiver operating characteristic curve (area under the curve $=0.6 ; 95 \%$ confidence interval $=0.3-0.8)$ indicated that $6 \mathrm{mmHg}$ was the optimal $\triangle$ LVEDP cutoff value for predicting CHF-related hospitalization. Therefore, the patients were divided into two groups: those with $\triangle \mathrm{LVEDP} \geq 6 \mathrm{mmHg}$ $(n=12)$ and those with $\triangle \operatorname{LVEDP}<6 \mathrm{mmHg}(n=56)$ [Figure 1].

Table 2 shows the baseline characteristics of the two groups. The patients with $\triangle$ LVEDP $<6 \mathrm{mmHg}$ and the patients with $\triangle$ LVEDP $\geq 6 \mathrm{mmHg}$ were matched in terms of all variables except for BMI, the values for which were higher in the group with $\triangle$ LVEDP $<6 \mathrm{mmHg}(P=0.036)$.

During the follow-up period (median duration [IQR]: 699 [413-994] days), eight patients (11.8\%) were hospitalized for CHF. Cox proportional hazards regression analysis showed that $\triangle$ LVEDP was an independent predictor of the risk of CHF-related hospitalization [Table 3]. In the Kaplan-Meier analysis, the rate of CHF-related hospitalization was significantly higher in the group with $\triangle \mathrm{LVEDP} \geq 6 \mathrm{mmHg}$ $(P=0.002)$ [Figure 2] than in the group with $\triangle \mathrm{LVEDP}<6 \mathrm{mmHg}$. Pre-LVG LVEDP values were not associated with CHF-related hospitalization.

\section{Discussion}

Our study showed that increased LVEDP after LVG is significantly associated with an increased risk of hospitalization for CHF. The risk was higher in the group with $\Delta$ LVEDP $\geq 6 \mathrm{mmHg}$ than in the group with $\triangle \mathrm{LVEDP}<6 \mathrm{mmHg}$. In contrast, ejection fraction (EF) and high LVEDP before LVG were not predictors of CHF-related hospitalization. This suggests that $\triangle \mathrm{LVEDP}$ is the better predictor of CHF-related hospitalization. Furthermore, unlike pulmonary capillary wedge pressure (PCWP) measurements, LVEDP can be

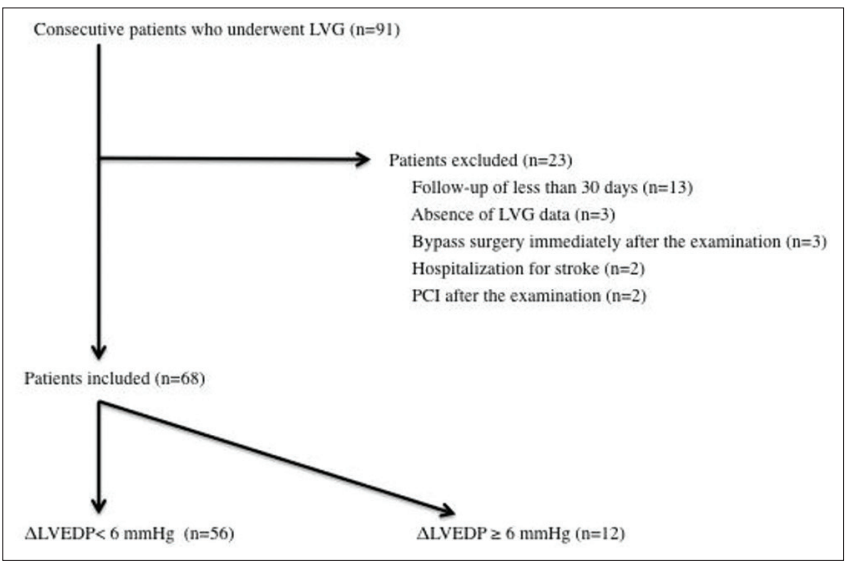

Figure 1: Study flow chart including number of patients underwent left ventriculography. LVG: left ventriculography; LVEDP: Left ventricular end-diastolic pressure; PCI: Percutaneous coronary angioplasty measured relatively simply with the same approach as that used for coronary angiography. The simplicity of LVEDP measurements is an important advantage.

Increased LVEDP causes CHF, although LVEDP-related CHF often resembles normal cardiac contractions. ${ }^{[17]}$ The fact that LVEDP is easily increased by the injection of a contrast agent suggests that the heart's ability to expand is reduced. In addition, volume loading is likely to increase the left atrial pressure, which would increase the risk of CHF. Moreover, the occurrence of heart failure with preserved $\mathrm{EF}$ (HFpEF) is possible. HFpEF is associated with hypertension in patients with heart failure. ${ }^{[18]}$ Given that many of our patients had hypertension and that few showed reduced EF values, our sample probably included many patients with HFpEF. Moreover, $\mathrm{HFpEF}$ is more common in women than in men, ${ }^{[19,20]}$ and in the present study, there were more women in the group with increased LVEDP than in the other group. However, the between-group difference in sex ratio was nonsignificant. EF levels did not differ between the two groups, which suggests that $\triangle$ LVEDP is a good indicator of diastolic dysfunction.

In this study, drug treatments before and after LVG did not differ between the two groups. Although there is currently no standard treatment for improving the prognosis of patients with $\mathrm{HFpEF}$, there are reports that angiotensin-converting enzyme inhibitors, $\beta$-blockers, and mineralocorticoid receptor blockers improve prognosis. ${ }^{[21-24]}$ If volume loading measurements indicate that a patient is susceptible to CHF, then pharmacotherapeutic interventions may reduce the risk of CHF-related hospitalization.

A similar study has examined the effects of iodixanol and iopamidol on hemodynamics. This study showed that an elevated PCWP and a decreased cardiac index (CI) are associated with adverse events. ${ }^{[25]}$ However, the association between increases in LVEDP and the risk of CHF-related hospitalization has not been investigated. Since no study has focused on the effect of increased LVEDP, our study was indeed

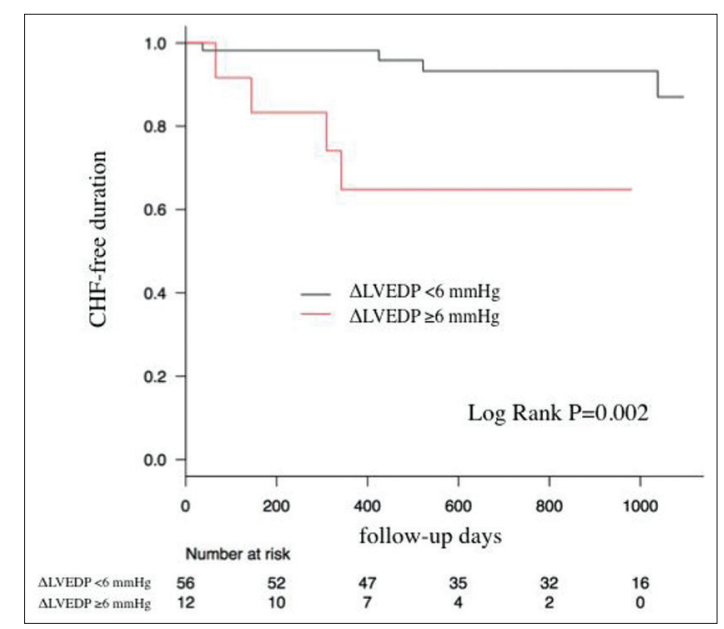

Figure 2: Kalpan-Meier for CHF-free duration patients in the group with LVEDP <6 mmHg. CHF: Congestive heart failure; $\triangle$ LVEDP: Left ventricular end-diastolic pressure 
Table 1: Patient characteristics in the included versus excluded groups

\begin{tabular}{|c|c|c|c|}
\hline & Included group $(n=68)$ & Excluded group $(n=23)$ & $P$ \\
\hline Age (IQR), years & $68(61-77)$ & $70(61-77)$ & 0.84 \\
\hline Male sex, $n(\%)$ & $41(60)$ & $27(70)$ & 0.47 \\
\hline BMI (SD), $\mathrm{kg} / \mathrm{m}^{2}$ & $24.3(3.7)$ & $24.4(3.4)$ & 0.91 \\
\hline \multicolumn{4}{|l|}{ Coexisting condition, $n(\%)$} \\
\hline Diabetes & $17(25)$ & $8(35)$ & 0.42 \\
\hline Hypertension & $50(74)$ & $17(74)$ & 1.0 \\
\hline Dyslipidemia & $42(62)$ & $15(65)$ & 0.81 \\
\hline Current smoking & $37(55)$ & $14(70)$ & 0.31 \\
\hline OMI & $7(10)$ & $2(9)$ & 1.0 \\
\hline Previous PCI & $18(27)$ & $6(26)$ & 1.0 \\
\hline Previous CABG & $1(2)$ & $1(4)$ & 0.44 \\
\hline Atrial fibrillation & $12(18)$ & $2(9)$ & 0.51 \\
\hline Family history & $10(16)$ & $1(5)$ & 0.28 \\
\hline $\mathrm{NYHA} \geq 2$ & $12(18)$ & $4(17)$ & 1.0 \\
\hline All cause death & $3(4)$ & $1(4)$ & 1.0 \\
\hline Heart rate (IQR), beats/min & $71(61-84)$ & $73(60-82)$ & 0.92 \\
\hline Systolic blood pressure (SD), mmHg & $129(23)$ & $138(22)$ & 0.078 \\
\hline Diastolic blood pressure (SD), $\mathrm{mmHg}$ & $67(11)$ & $69(15)$ & 0.38 \\
\hline Contrast agent usage in all procedures (IQR), $\mathrm{mL}$ & $130(105-171)$ & $115(105-155)$ & 0.37 \\
\hline \multicolumn{4}{|l|}{ Laboratory results } \\
\hline Baseline hemoglobin level (SD), g/L & $14.0(1.7)$ & $13.9(1.0)$ & 0.73 \\
\hline Baseline creatinine (SD), $\mu \mathrm{mol} / \mathrm{L}$ & $0.81(0.18)$ & $0.92(0.21)$ & $0.019 *$ \\
\hline Uric acid level (SD), mg/dL & $5.7(1.6)$ & $5.5(1.1)$ & 0.74 \\
\hline eGFR (SD), $\mathrm{mL} / \mathrm{min} / 1.73 \mathrm{~m}^{2}$ & $67(14)$ & $64(15)$ & 0.39 \\
\hline \multicolumn{4}{|l|}{ Medications before LVG, $n(\%)$} \\
\hline Aspirin & $25(37)$ & $17(74)$ & $0.003^{*}$ \\
\hline Prasugrel & $1(2)$ & $2(9)$ & 0.16 \\
\hline Clopidogrel & $15(22)$ & $5(22)$ & 1.0 \\
\hline $\mathrm{ARB}$ & $16(24)$ & $9(39)$ & 0.18 \\
\hline ACE inhibitor & $6(9)$ & $4(17)$ & 0.27 \\
\hline$\beta$-Blocker & $9(13)$ & $2(9)$ & 0.79 \\
\hline Statin & $26(38)$ & $13(57)$ & 0.15 \\
\hline ACE inhibitor + ARB & $22(32)$ & $13(57)$ & 0.054 \\
\hline \multicolumn{4}{|l|}{ In-hospital medications, $n(\%)$} \\
\hline Aspirin & $47(69)$ & $20(87)$ & 0.11 \\
\hline Prasugrel & $13(19)$ & $6(26)$ & 0.56 \\
\hline Clopidogrel & $15(22)$ & $3(13)$ & 0.55 \\
\hline $\mathrm{ARB}$ & $26(38)$ & $8(35)$ & 0.81 \\
\hline ACE inhibitor & $10(15)$ & $5(22)$ & 0.52 \\
\hline$\beta$-Blocker & $18(27)$ & $5(22)$ & 0.79 \\
\hline Statin & $46(68)$ & $16(70)$ & 1.0 \\
\hline ACE inhibitor + ARB & $36(53)$ & $13(57)$ & 0.81 \\
\hline \multicolumn{4}{|l|}{ LVG data (IQR) } \\
\hline Pre-LVG LVEDP, mmHg & $10(8-14)$ & $10(8-13)$ & 0.78 \\
\hline LVEF, \% & $64.1(56.2-68.0)$ & $64.5(62.7-69.8)$ & 0.40 \\
\hline LVSV, mL & $49.0(41.0-66.1)$ & $55.1(41.9-68.8)$ & 0.63 \\
\hline LVSVI, $\mathrm{mL} / \mathrm{m}^{2}$ & $32.2(25.4-40.6)$ & $33.7(24.4-38.9)$ & 0.096 \\
\hline LVEDV, $\mathrm{mL}$ & $79.2(65.5-117.4)$ & $83.9(70.2-107.1)$ & 0.67 \\
\hline LVEDVI, $\mathrm{mL} / \mathrm{m}^{2}$ & $51.3(40.6-68.5)$ & $50.5(37.8-66.7)$ & 0.99 \\
\hline LVESV, mL & $29.8(24.6-39.8)$ & $28.7(19.1-38.0)$ & 0.54 \\
\hline LVESVI, $\mathrm{mL} / \mathrm{m}^{2}$ & $17.6(14.4-24.2)$ & $18.1(13.7-22.8)$ & 0.86 \\
\hline
\end{tabular}

Results are presented as $n(\%)$, mean (SD), or median (IQR). ${ }^{*} P<0.05$. ACE: Angiotensin-converting enzyme inhibitor, ARB: Angiotensin II receptor blocker, BMI: Body mass index, CABG: Coronary artery bypass surgery, eGFR: Estimated glomerular filtration rate, IQR: Interquartile range, LVEDP: Left ventricular end-diastolic pressure, LVEDV: Left ventricular end-diastolic volume, LVEDVI: LVEDV index (i.e., LVEDV indexed to the body surface area), LVEF: Left ventricular ejection fraction, LVESV: Left ventricular end-systolic volume, LVESVI: LVESV index, LVG: Left ventriculography, LVSV: Left ventricular stroke volume, LVSVI: LVSV index, NYHA: New York Heart Association functional classification, OMI: Old myocardial infarction, PCI: Percutaneous coronary angioplasty, SD: Standard deviation 
Table 2: Characteristics of patients with $\Delta$ left ventricular end-diastolic pressure $<6 \mathrm{mmHg}$ versus patients with $\Delta$ left ventricular end-diastolic pressure $\geq 6 \mathrm{mmHg}$

\begin{tabular}{|c|c|c|c|}
\hline & $\Delta$ LVEDP $<6 \mathrm{mmHg}(n=56), n(\%)$ & $\Delta$ LVEDP $\geq 6 \mathrm{mmHg}(n=12), n(\%)$ & $P$ \\
\hline Age (IQR), years & $67(61-75)$ & $71(69-79)$ & 0.088 \\
\hline Age $>75$ years, $n(\%)$ & $14(25)$ & $5(42)$ & 0.29 \\
\hline Male sex, $n(\%)$ & $37(66)$ & $4(33)$ & 0.052 \\
\hline BMI (SD), $\mathrm{kg} / \mathrm{m}^{2}$ & $24.7(3.5)$ & $22.3(3.8)$ & $0.036^{*}$ \\
\hline \multicolumn{4}{|l|}{ Coexisting condition, $n(\%)$} \\
\hline Diabetes & $15(27)$ & $2(17)$ & 0.72 \\
\hline Hypertension & $41(73)$ & $9(75)$ & 1.0 \\
\hline Dyslipidemia & $38(68)$ & $4(33)$ & 0.46 \\
\hline Current smoking & $32(58)$ & $5(42)$ & 0.35 \\
\hline Previous OMI & $7(13)$ & 0 & 0.34 \\
\hline Previous PCI & $17(30)$ & $1(8)$ & 0.16 \\
\hline Previous CABG & $1(1.8)$ & 0 & 1.0 \\
\hline Atrial fibrillation & $11(20)$ & $1(8)$ & 0.68 \\
\hline Family history & $7(13)$ & $3(27)$ & 0.36 \\
\hline $\mathrm{NYHA} \geq 2$ & $9(16)$ & $3(25)$ & 0.43 \\
\hline All cause death & $2(4)$ & $1(8)$ & 0.45 \\
\hline Heart rate (IQR), beats/min & $71(60-83)$ & $77(66-88)$ & 0.18 \\
\hline Systolic blood pressure (SD), mmHg & $129(23.5)$ & $125(19.3)$ & 0.57 \\
\hline Diastolic blood pressure (SD), $\mathrm{mmHg}$ & $67.5(11.3)$ & $63.8(8.6)$ & 0.24 \\
\hline Contrast agent usage in all procedures (IQR), $\mathrm{mL}$ & $130(105-176)$ & $132(103-140)$ & 0.39 \\
\hline \multicolumn{4}{|l|}{ Laboratory results } \\
\hline Baseline hemoglobin level (SD), g/L & $14.1(1.7)$ & $13.6(1.8)$ & 0.33 \\
\hline Baseline creatinine level (SD), $\mu \mathrm{mol} / \mathrm{L}$ & $0.82(0.16)$ & $0.76(0.25)$ & 0.27 \\
\hline Uric acid level (SD), mg/dL & $5.8(1.5)$ & $5.1(1.7)$ & 0.30 \\
\hline eGFR (SD), $\mathrm{mL} / \mathrm{min} / 1.73 \mathrm{~m}^{2}$ & $68.5(16.2)$ & $60.7(19.4)$ & 0.53 \\
\hline \multicolumn{4}{|l|}{ Medications before LVG, $n(\%)$} \\
\hline Aspirin & $21(38)$ & $4(33)$ & 1.0 \\
\hline Prasugrel & $1(2)$ & 0 & 1.0 \\
\hline Clopidogrel & $15(27)$ & 0 & 0.055 \\
\hline $\mathrm{ARB}$ & $14(25)$ & $2(18)$ & 1.0 \\
\hline ACE inhibitor & $5(9)$ & $1(9)$ & 1.0 \\
\hline$\beta$-Blocker & $6(11)$ & $3(25)$ & 0.19 \\
\hline Statin & $23(41)$ & $3(25)$ & 0.35 \\
\hline ACE inhibitor + ARB & $19(34)$ & $3(25)$ & 0.74 \\
\hline \multicolumn{4}{|l|}{ In-hospital medications, $n(\%)$} \\
\hline Aspirin & $37(66)$ & $10(83)$ & 0.32 \\
\hline Prasugurel & $10(18)$ & $3(25)$ & 0.69 \\
\hline Clopidogrel & $14(25)$ & $1(8)$ & 0.28 \\
\hline $\mathrm{ARB}$ & $21(38)$ & $5(42)$ & 1.0 \\
\hline ACE inhibitor & $8(14)$ & $2(17)$ & 1.0 \\
\hline$\beta$-blocker & $13(23)$ & $5(42)$ & 0.28 \\
\hline Statin & $39(70)$ & $7(58)$ & 0.51 \\
\hline ACE inhibitor + ARB & $29(52)$ & $7(58)$ & 0.76 \\
\hline \multicolumn{4}{|l|}{ LVG data (IQR) } \\
\hline Pre-LVG LVEDP, mmHg & $10(8-13)$ & $10(6-15)$ & 0.99 \\
\hline LVEF, \% & $63.9(56.2-68.6)$ & $65.2(52.4-66.4)$ & 0.71 \\
\hline LVSV, mL & $51.8(41.8-69.0)$ & $47.3(38.5-49.0)$ & 0.21 \\
\hline LVSVI, $\mathrm{mL} / \mathrm{m}^{2}$ & $32.5(25.8-41.4)$ & $31.2(26.4-35.4)$ & 0.81 \\
\hline LVEDV, mL & $82(66-117)$ & $74.7(62.6-121.5)$ & 0.93 \\
\hline LVEDVI, $\mathrm{mL} / \mathrm{m}^{2}$ & $51.3(40.0-68.7)$ & $51.0(44.9-72.5)$ & 0.42 \\
\hline LVESV, mL & $30.3(24.5-38.8)$ & $25.5(23.6-69.3)$ & 0.77 \\
\hline
\end{tabular}


Table 2: Contd...

\begin{tabular}{|c|c|c|c|}
\hline & $\Delta$ LVEDP $<6 \mathrm{mmHg}(n=56), n(\%)$ & $\Delta$ LVEDP $\geq 6 \mathrm{mmHg}(n=12), n(\%)$ & $P$ \\
\hline LVESVI, $\mathrm{mL} / \mathrm{m}^{2}$ & $17.8(14.4-23.8)$ & $17.0(15.3-41.9)$ & 0.51 \\
\hline
\end{tabular}

Table 3: Results of univariate and multivariate Cox proportional hazards analyses of congestive heart failure-related hospitalization risk

\begin{tabular}{|c|c|c|c|c|}
\hline Variable & Univariate analysis & $P$ & Multivariate analysis & $P$ \\
\hline Age $>75$ years & $4.3(1.1-16.3)$ & $0.031 *$ & $2.9(0.6-15.0)$ & 0.21 \\
\hline Male sex & $1.7(0.4-6.8)$ & 0.46 & & \\
\hline Diabetes & $0.4(0.05-3.3)$ & 0.40 & & \\
\hline Current smoker & $0.7(0.2-3.0)$ & 0.67 & & \\
\hline Baseline hemoglobin level $<11 \mathrm{~g} / \mathrm{L}$ & $3.5(0.4-30.1)$ & 0.25 & & \\
\hline Dyslipidemia & $0.5(0.1-2.2)$ & 0.40 & & \\
\hline $\mathrm{LVEF}<40 \%$ & $1.8(0.2-14.6)$ & 0.59 & & \\
\hline $\mathrm{BMI}>24 \mathrm{~kg} / \mathrm{m}^{2}$ & $1.7(0.4-7.3)$ & 0.45 & & \\
\hline Hypertension & $1.0(0.2-5.1)$ & 0.99 & & \\
\hline $\mathrm{NYHA} \geq 2$ & $9.7(2.3-40.6)$ & $0.002 *$ & $2.1(0.3-16.6)$ & 0.48 \\
\hline CKD & $3.7(1.0-14.0)$ & $0.05^{*}$ & $6.4(1.0-42.2)$ & $0.052 *$ \\
\hline Atrial fibrillation & $4.3(1.1-17.4)$ & $0.039^{*}$ & $9.3(0.5-164.8)$ & 0.13 \\
\hline$\Delta$ LVEDP $\geq 6 \mathrm{mmHg}$ & $7.4(1.6-33.2)$ & $0.009^{*}$ & $8.4(1.3-55.7)$ & $0.028 *$ \\
\hline
\end{tabular}

Hazards ratios with $95 \%$ CIs. $* P<0.05$. CI: Confidence interval, BMI: Body mass index, CKD: Chronic kidney disease, LVEDP: Left ventricular

end-diastolic pressure, LVEF: Left ventricular ejection fraction, NYHA: New York Heart Association functional classification

novel. In the future, it will be important to further investigate the effects of increased LVEDP and compare its usefulness in predicting adverse outcomes with that of PCWP and the CI.

This study has some limitations. First, this was a retrospective study conducted at a single center where echocardiography and brain natriuretic peptide measurements were not routinely performed. Second, BMI values tended to be lower in the group with $\triangle$ LVEDP $\geq 6 \mathrm{mmHg}$ than in the group with $\triangle$ LVEDP $<6$ $\mathrm{mmHg}$. Therefore, the degree of volume loading with a contrast agent could have been relatively high in that group. In addition, the appropriate cutoff $\triangle$ LVEDP value may differ depending on the type and amount of contrast agent. Third, in this study, it was not possible to determine whether increases in LVEDP outperformed PCWP at predicting CHF-related hospitalization. Fourth, because this study included few patients with low EF values, we were unable to determine how $\triangle$ LVEDP values affect patients with low EF. Fifth, a center-specific bias cannot be excluded. Prospective clinical trials and large multicenter collaborative clinical trials will be required to determine the optimal cutoff $\triangle$ LVEDP value and to determine whether PCWP is a more useful indicator than $\triangle$ LVEDP. The small sample size is also limitation.

\section{Conclusions}

Our findings suggest that an increased LVEDP value after LVG is a significant independent predictor of CHF-related hospitalization. Measuring $\triangle$ LVEDP may enable early interventions in patients who are likely to be hospitalized for CHF.

\section{Financial support and sponsorship}

Nil.

\section{Conflicts of interest}

There are no conflicts of interest.

\section{RefEREnCES}

1. Bagai A, Armstrong PW, Stebbins A, Mahaffey KW, Hochman JS, Weaver WD, et al. Prognostic implications of left ventricular end-diastolic pressure during primary percutaneous coronary intervention for ST-segment elevation myocardial infarction: Findings from the Assessment of Pexelizumab in Acute Myocardial Infarction study. Am Heart J 2013;166:913-9.

2. Planer D, Mehran R, Witzenbichler B, Guagliumi G, Peruga JZ, Brodie BR, et al. Prognostic utility of left ventricular end-diastolic pressure in patients with ST-segment elevation myocardial infarction undergoing primary percutaneous coronary intervention. Am J Cardiol 2011;108:1068-74.

3. Mielniczuk LM, Lamas GA, Flaker GC, Mitchell G, Smith SC, Gersh BJ, et al. Left ventricular end-diastolic pressure and risk of subsequent heart failure in patients following an acute myocardial infarction. Congest Heart Fail 2007;13:209-14.

4. Salem R, Denault AY, Couture P, Bélisle S, Fortier A, Guertin MC, et al. Left ventricular end-diastolic pressure is a predictor of mortality in cardiac surgery independently of left ventricular ejection fraction. Br J Anaesth 2006;97:292-7.

5. Cubeddu RJ, Don CW, Horvath SA, Gupta PP, Cruz-Gonzalez I, 
Witzke C, et al. Left ventricular end-diastolic pressure as an independent predictor of outcome during balloon aortic valvuloplasty. Catheter Cardiovasc Interv 2014;83:782-8.

6. Saito D, Nakanishi R, Watanabe I, Yabe T, Okubo R, Amano H, et al. Combined assessment of left ventricular end-diastolic pressure and ejection fraction by left ventriculography predicts long-term outcomes of patients with ST-segment elevation myocardial infarction. Heart Vessels 2018;33:453-61.

7. Porteous MK, Ky B, Kirkpatrick JN, Shinohara R, Diamond JM, Shah RJ, et al. Diastolic dysfunction increases the risk of primary graft dysfunction after lung transplant. Am J Respir Crit Care Med 2016;193:1392-400.

8. Kirtane AJ, Bui A, Murphy SA, Karmpaliotis D, Kosmidou I, Boundy K, et al. Association of epicardial and tissue-level reperfusion with left ventricular end-diastolic pressures in ST-elevation myocardial infarction. J Thromb Thrombolysis 2004;17:177-84.

9. Van Herck PL, Carlier SG, Claeys MJ, Haine SE, Gorissen P, Miljoen H, et al. Coronary microvascular dysfunction after myocardial infarction: Increased coronary zero flow pressure both in the infarcted and in the remote myocardium is mainly related to left ventricular filling pressure. Heart 2007;93:1231-7.

10. Sasayama S, Nonogi H, Kawai C, Fujita M, Eiho S, Kuwahara M. Automated method for left ventricular volume measurement by cineventriculography with minimal doses of contrast medium. Am J Cardiol 1981;48:746-53.

11. Tani M, Handa S, Ohnishi S. Digital subtraction ventriculography and aortography. Shinzo 1984;16:1231-9.

12. Slutsky R, Higgins C, Costello D, Hooper W, LeWinter MM. Mechanism of increase in left ventricular end-diastolic pressure after contrast ventriculography in patients with coronary artery disease. Am Heart J 1983;106:107-13.

13. Sullivan ID, Wainwright RJ, Reidy JF, Sowton E. Comparative trial of iohexol 350, a non-ionic contrast medium, with diatrizoate (Urografin 370 ) in left ventriculography and coronary arteriography. Br Heart J 1984;51:643-7.

14. Koeda T, Motegi I, Ichikawa T, Suzuki T, Kato M. Changes in hemodynamics due to the contrast medium during left ventriculography. Angiology 1987;38:825-32.
15. Matsuo S, Imai E, Horio M, Yasuda Y, Tomita K, Nitta K, et al. Revised equations for estimated GFR from serum creatinine in Japan. Am J Kidney Dis 2009;53:982-92.

16. Kanda Y. Investigation of the freely available easy-to-use software 'EZR' for medical statistics. Bone Marrow Transplant 2013;48:452-8.

17. Mascherbauer J, Zotter-Tufaro C, Duca F, Binder C, Koschutnik M, Kammerlander AA, et al. Wedge pressure rather than left ventricular end-diastolic pressure predicts outcome in heart failure with preserved ejection fraction. JACC Heart Fail 2017;5:795-801.

18. Tsuchihashi-Makaya M, Hamaguchi S, Kinugawa S, Yokota T, Goto D, Yokoshiki $\mathrm{H}$, et al. Characteristics and outcomes of hospitalized patients with heart failure and reduced vs preserved ejection fraction. Report from the Japanese Cardiac Registry of Heart Failure in Cardiology (JCARE-CARD). Circ J 2009;73:1893-900.

19. Sakata Y, Miyata S, Nochioka K, Miura M, Takada T, Tadaki S, et al. Gender differences in clinical characteristics, treatment and long-term outcome in patients with stage C/D heart failure in Japan. Report from the CHART-2 study. Circ J 2014;78:428-35.

20. Daimon M, Watanabe H, Abe Y, Hirata K, Hozumi T, Ishii K, et al. Gender differences in age-related changes in left and right ventricular geometries and functions. Echocardiography of a healthy subject group. Circ J 2011;75:2840-6.

21. Pitt B, Pfeffer MA, Assmann SF, Boineau R, Anand IS, Claggett B, et al. Spironolactone for heart failure with preserved ejection fraction. New Engl J Med 2014;370:1383-92.

22. Lund LH, Benson L, Dahlström U, Edner M. Association between use of renin-angiotensin system antagonists and mortality in patients with heart failure and preserved ejection fraction. JAMA 2012;308:2108-17.

23. Liu F, Chen Y, Feng X, Teng Z, Yuan Y, Bin J. Effects of beta-blockers on heart failure with preserved ejection fraction: A meta-analysis. PLoS One 2014;9:e90555.

24. Lund LH, Benson L, Dahlström U, Edner M, Friberg L. Association between use of $\beta$-blockers and outcomes in patients with heart failure and preserved ejection fraction. JAMA 2014;312:2008-18.

25. Denardo SJ, Vock DM, Schmalfuss CM, Young GD, Tcheng JE, O'Connor CM. Baseline Hemodynamics and response to contrast media during diagnostic cardiac catheterization predict adverse events in heart failure patients. Circ Heart Fail 2016;9: e002529. 